\title{
Terceirização de Desenvolvimento de Software em Body Shop: uma Proposta para Diminuir os Riscos
}

\author{
Daniel Schreiber ${ }^{1,2}$, Cleiton dos Santos Garcia ${ }^{1}$, Dionei Domingos ${ }^{2}$, Kelly Bettio ${ }^{1}$, \\ Sheila Reinehr ${ }^{1}$, Andreia Malucelli ${ }^{1}$ \\ ${ }^{1}$ Programa de Pós-Graduação em Informática (PPGIa) \\ Pontifícia Universidade Católica do Paraná (PUC-PR) \\ Curitiba - PR - Brasil \\ ${ }^{2}$ Gati Tecnologia da Informação \\ Joinville - SC - Brasil \\ \{xiraba, cleitonsg\}@gmail.com, dionei@gati.inf.br, \\ \{kelly.bettio, sheila.reinehr\}@pucpr.br, malu@ppgia.pucpr.br
}

\begin{abstract}
Resumo. Clientes e fornecedores trabalham em parceria para atender as necessidades do mercado, se comprometendo com a qualidade do produto final. No contexto de TI, a realização de body shop se tornou uma prática comum, devido à alta celeridade das mudanças do ambiente. Contudo, a realização de terceirização apresenta riscos que precisam ser reduzidos ou mesmo evitados. Este artigo relata as atividades desenvolvidas e lições aprendidas na realização de body shop em desenvolvimento de software, propondo um conjunto de ações preventivas para melhorar a qualidade $e$ diminuir os riscos na terceirização.
\end{abstract}

Abstract. Customers and suppliers work together to meet market needs, where both commit with final product quality. In IT context, conducting body shop has become a common practice, due to the high speed of environment changes. However, there are risks in the outsourcing process that must be mitigated or even avoided. This paper describes body shop activities and lessons learned in software development, proposing a set of mitigating actions for improving software quality and reducing risks in outsourcing.

\section{Introdução}

A área de TI tem buscado alternativas para redução de custos com mão de obra, bem como, para suprir a falta de recursos humanos qualificados para atender a demanda de um mercado em crescente expansão (Nakatsu and Iacovou 2009). Neste contexto a terceirização ganha importância a partir do momento que as empresas começam a redefinir suas operações, a racionalizar recursos, e a funcionar com estruturas mais enxutas e flexíveis (Sá, Bomtempo and Quental 1998).

Segundo Smuts et al (2010), uma das estratégias mais utilizadas para a redução de custos em Tecnologia da Informação é a terceirização. Terceirização é o ato de transferir atividades e responsabilidades para um fornecedor externo (Chase, Aquilano and Jacobs 2004).

Do ponto de vista da alta administração, segundo Prado e Takaoka (2002), a terceirização é a estratégia chave que permite: responder à rápida internacionalização 
dos negócios e à mudança de regras; aumentar o retorno sobre os investimentos; manter-se atualizado diante da célere evolução tecnológica; criar diferenciação diante dos competidores; e, responder à crescente falta de profissionais qualificados na área de Tecnologia da Informação (TI).

De acordo com Lacity e Hirschheim (1993), em TI existem três tipos básicos de terceirização:

- Body shop: consiste em desenvolver as atividades nas dependências do cliente e o gerenciamento da mão de obra é responsabilidade do contratante.

- Gerenciamento de projeto: é a terceirização de um projeto específico ou parte dele, onde as atividades e o gerenciamento são realizados pelo fornecedor.

- Terceirização total: é realizado totalmente pelo fornecedor, onde uma parte significante de um sistema de informação é desenvolvida.

O body shop é o tipo de terceirização objeto deste estudo, por ser utilizado como forma de atender curtas demandas de desenvolvimento e/ou manutenção de sistemas, onde não é viável contratar um novo profissional para desenvolver um projeto em específico. Empresas de diversos ramos buscam mão de obra temporária para atender demandas de curta duração, em áreas específicas, como manutenção em servidores, banco de dados, ERP, entre outros (Mansur 2007).

Entretanto, a terceirização apresenta riscos como: falta de experiência do cliente em gerenciar terceirização; equipe do fornecedor sem conhecimento do negócio e não qualificada tecnicamente; falta de comunicação entre cliente e fornecedor; falha por parte dos fornecedores em cumprir com seus compromissos contratuais; perda da capacidade de inovação e falta de aprendizagem organizacional; disputas sobre obrigações contratuais; roubo de propriedade intelectual; falha na previsão de custos para realização das atividades; ameaça de moralidade por parte dos envolvidos; tecnologias incompatíveis (Earl 1996; Nakatsu and Iacovou 2009)

Simões, Santos e Rocha (2010) acrescentam que a terceirização não é simples e existem muitos casos de insucesso. Entretanto a adoção de práticas de melhoria de processos permite maximizar a produtividade e utilizar efetivamente as tecnologias, propiciando assim a manutenção da competitividade nas organizações (SEI 2006).

Neste contexto, este relato tem como objetivo apresentar a experiência obtida com a atividade de body shop realizada pela empresa Gati, prestadora de serviço em desenvolvimento e manutenção de sistemas.

Este relato está assim organizado: a seção 2 descreve a empresa estudada; a seção 3 descreve o modelo de trabalho adotado pela Gati, com ênfase nos três principais riscos da terceirização; a seção 4 relata as lições aprendidas e as ações preventivas para evitar os riscos na terceirização; e, por fim, a seção 5 apresenta as considerações finais.

\section{Cenário da Organização}

A Gati é uma fábrica de software e consultoria sediada em Joinville (SC) que está a mais de dez anos no mercado e possui operações nos estados de Santa Catarina, Minas Gerais, São Paulo, Bahia, Amazonas e Paraná. Atualmente conta com mais de 70 profissionais (desenvolvedores, analistas, consultores de negócio e gerentes de projeto) que possuem grande experiência nas tecnologias Progress, 4GL, Java, Flex, PHP, ASP, 
C, C\#, .Net, Superwaba, Delphi, atuando também em outras vertentes como aplicações móveis (automação de vendas e industrial), aplicações para Web (portais, gestão de projetos, sites, marketing web) e outsourcing de infraestrutura e segurança.

A partir de 2010, a GATI se tornou uma Extended Business Program (EBM) da SAP, e com isso passou a ser também um fornecedor de produtos e serviços da SAP para Santa Catarina. Dentre os projetos já executados nestes anos, estão: automação, integração com coletores de dados, etiquetas, balanças, contadores, sequenciamento de esteira de produtos; (WMS); controle de serviços terceirizados; desenvolvimento boletos bancários; Nota Fiscal Eletrônica (solução completa com a geração e importação para o ERP); Otimizador de corte; Planejamento de mão-de-obra; Planejamento de produção (APS); portais corporativos Web; quiosque gestão de capital humano; simulador de embarque; sped (fiscal e contábil), dentre outros.

Devido a sua expansão, a Gati desenvolveu sua própria metodologia de trabalho, seguindo algumas restrições impostas pelo mercado. A próxima seção apresenta esta metodologia e discute alguns aspectos referentes aos riscos encontrados na terceirização.

\section{Modelo de Trabalho Gati - RQG}

Com o objetivo de diminuir os riscos da terceirização, em especial na prática de Body Shop, a Gati desenvolveu um modelo de trabalho denominado Requisitos de Qualidade Gati (RQG). Este modelo define melhorias nas disciplinas de Gerência de Projetos e Requisitos, com ênfase na padronização da documentação, comunicação e gestão das atividades, seguindo padrões especificados pelo CMMI (Capability Maturity Model Integration) (SEI 2006).

Uma pesquisa realizada por Nakatsu e Iacovou (2009), objetivou levantar questões relevantes sobre a importância dos fatores de riscos na terceirização doméstica e na modalidade offshore. Os entrevistados foram os principais gestores em TI dos Estados Unidos, com experiência em gerenciamento de projetos e certificados pelo Project Management Institute (PMI). A pesquisa resultou na classificação dos dez fatores de riscos que mais influenciam na terceirização e os três mais citados foram: falha na comunicação e entendimento dos requisitos, falta de comunicação entre os envolvidos e controle ineficaz das alterações.

Algumas empresas têm procurado desenvolver técnicas que possam diminuir estes riscos com a terceirização. Uma destas empresas é a Gati, que adotou o gerenciamento e a rastreabilidade dos requisitos, em conjunto com a melhoria no processo de desenvolvimento e interação com os clientes.

Com base no resultado da pesquisa realizada por Nakatsu e Iacovou (2009), são descritas algumas das etapas do modelo RQG da Gati, enfatizando as medidas tomadas para minimizar ou mesmo evitar os três principais riscos levantados.

\subsection{Risco 1: Falha na comunicação e entendimento dos requisitos}

O primeiro ponto para iniciar um projeto, novo ou de manutenção na Gati, é estabelecer critérios e regras. Estas regras são criadas por meio de entrevistas com o cliente, onde suas necessidades e desejos são anotados e formalizados em um documento. O resultado desta entrevista gera o primeiro artefato: Documento de visão. 
- Levantamento de Stakeholderrequest - requisitos solicitados pelo cliente são descritos na forma como foram solicitados (mesmo que tecnicamente pareçam incorretos). Uma stakeholderrequest é a forma como o cliente consegue se referir ao produto. Estas informações podem ser fornecidas de várias maneiras entre elas: documental (documento de edital, por exemplo), ou citadas durante reuniões ou entrevistas. $\mathrm{O}$ artefato de armazenamento das stakeholderrequest é o Documento de Visão, que por sua vez será gerado durante o processo de análise de negócio;

O segundo passo é a transcrição das solicitações levantadas na etapa anterior em documentos formais de requisitos, onde de maneira clara e objetiva, detalha o que o sistema deve fazer e também o que não deve fazer. Nesta etapa são criados três novos artefatos.

- Levantamento de Requisitos Funcionais de Negócio - decodificação de stakeholderrequests que tenham relação com funcionalidades que envolvam aspectos de execução de negócio do produto de software (por exemplo, uma periodicidade de execução de uma função, uma fórmula para cálculo, etc.). $\mathrm{O}$ artefato de armazenamento dos Requisitos Funcionais de Negócio é a Lista de Requisitos, que por sua vez será gerado durante o processo de análise do sistema;

- Levantamento de Requisitos Funcionais de Interface - decodificação de stakeholderrequests que tenham relação com funcionalidades que envolvam operação de telas ou relatórios do produto de software. O artefato de armazenamento dos Requisitos Funcionais de Interface é a Lista de Requisitos, que por sua vez será gerado durante o processo de análise do sistema;

- Levantamento de Requisitos Não Funcionais - decodificação de stakeholderrequests que não tenham relação com funcionalidades, mas com aspectos gerenciais e/ou estritamente técnicos do projeto de software. Este tipo de requisito é também chamado de Premissa ou Restrição. O artefato de armazenamento dos Requisitos Não Funcionais é a Lista de Requisitos, que por sua vez será gerada durante o processo de análise do sistema;

Os requisitos são gerenciados pela ferramenta case Enterprise Architect tendo como base os stakeholdersrequest, sendo catalogados e rastreados entre si e entre os demais artefatos do projeto, como casos de uso, diagramas de classe, sequência, e outros que venham a ser gerados durante o desenvolvimento. A comunicação, interação com o cliente e gerenciamento do projeto é realizada pela ferramenta dotProject, customizada para atender as premissas do RQG.

A Figura 1 ilustra o processo de gestão de requisitos, baseado nas práticas do CMMI para o nível 3 de maturidade, adaptados para as atividades de prestação de serviços em body shop desempenhados pela Gati.

O processo de comunicar e validar os requisitos é constante, sendo realizado não só no final, mas durante todo o processo de especificação dos requisitos. Da mesma forma, o processo de gerenciamento de requisitos é executado desde o início até o final das atividades, sendo este definido conforme as necessidades, tipo, e limites financeiros impostos pelo cliente. 


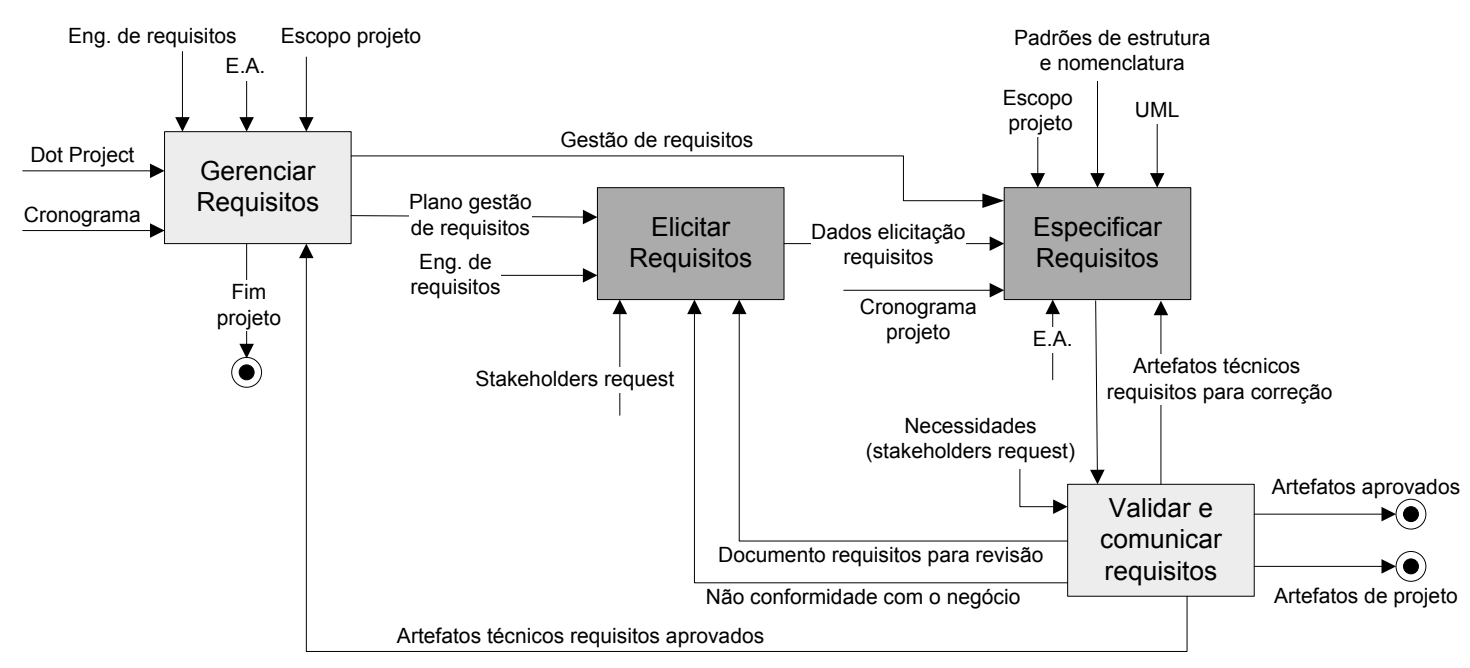

Figura 1. Processo de desenvolvimento de requisitos da Gati.

\subsection{Risco 2: Falta de comunicação}

Não são apenas os gerentes e os patrocinadores os responsáveis pela comunicação, mas todos os envolvidos no projeto. Para isso, todos precisam ser proativos e comunicativos, antecipando os riscos e problemas que possam impactar o projeto.

A Gati utiliza o artifício de treinamento para estimular a comunicação e manter os envolvidos, tanto funcionários como o próprio cliente, atualizados. A seguir são citadas as principais formas de especialização na comunicação adotadas pela Gati.

Regresso: o objetivo é a atualização do profissional, por meio de workshops internos com a equipe e demais profissionais que estejam atuando em cliente, além de fornecer suporte e apoio técnico para qualquer tipo de problema ou dúvida relacionada aos trabalhos. Liderado pela gerência e protagonizado pelos demais integrantes da equipe, são apresentadas e discutidas atividades técnicas, por meio de breves relatos de experiências, trocas de conhecimentos e as atuais atividades de cada profissional. Também são discutidas questões estratégicas, ligadas aos clientes, como a expansão das atividades, novos negócios, novas parcerias e técnicas de comportamentos.

Touchpoint: por meio dos touchpoints as interações com os clientes são aperfeiçoadas, permitindo que a equipe se torne mais consciente em relação às atividades a serem desenvolvidas. Os touchpoints também ajudam no compartilhamento com toda a organização, das atividades em desenvolvimento que estão gerando resultados positivos (Blomberg, Cefkin and Rankin 2010).

Iteratividade com o cliente: envolver-se nas atividades do cliente, realizar visitas e convidar o cliente para participar de workshops promovidos internamente na Gati aumentaram os laços entre ambas às partes. Contudo, é imprescindível saber ouvir as críticas dos avaliadores de forma construtiva e evitar criar conflitos devido a divergências na interpretação dos resultados e dos processos existentes.

\subsection{Risco 3: Controle ineficaz das alterações}

Ao longo que um projeto avança, seus limites têm como tendência serem ampliados. Não somente os limites do projeto, mas também os custos, impactos de tempo e qualidade são afetados negativamente (Nakatsu and Iacovou 2009). 
Independente da responsabilidade do cliente realizar todo e qualquer tipo de gerenciamento, a Gati realiza o gerenciamento de requisitos, recursos humanos e administra reuniões com o cliente e pessoal envolvido nas tarefas. Isso ajuda a obter melhores resultados técnicos e gerenciais.

\section{Lições aprendidas}

Em prestação de serviços, as pessoas envolvidas nos trabalhos são de vital importância para o sucesso de uma organização, pois são elas que lidam diretamente com o cliente e podem ajudar a melhorar ou não a qualidade do serviço prestado (Lima et al. 2009).

Em decorrência das atividades executadas diretamente nas dependências dos clientes, os profissionais envolvidos ficam isolados da equipe que trabalha na Gati. Em consequência, alguns pontos negativos podem ser destacados:

- Falta de suporte: problemas ou dúvidas técnicas surgem o tempo todo, e, dependendo do local de trabalho, não é possível buscar a solução em tempo hábil;

- Tomada de decisões fora do escopo: em consequência da ausência, ou da comunicação não ser tão eficaz entre o profissional alocado no cliente e a fornecedora de serviço, algumas decisões de projetos precisam ser tomadas em um período curto de tempo. Porém, estas decisões nem sempre estão em conformidade com os requisitos e objetivos primários do projeto e podem ocasionar desvios;

- Choque de cultura: cada empresa tem sua própria cultura. É preciso se adaptar a cada cliente, entendendo a cultura e agindo dentro dos padrões da empresa. Para conseguir fazer isso é importante a percepção, a comunicação e o comprometimento com as normas do ambiente de trabalho do contratante;

- Sincronização com as atividades da empresa: quem está no cliente não interage com as novidades da fábrica de software, assim como com as novidades do mercado em inovações e novas tecnologias, afetando negativamente seu desempenho e imagem perante o cliente. Quando o cliente contrata um serviço, espera-se que este seja executado nos mais altos padrões, com o que há de melhor disponível no mercado.

Com base nos riscos da terceirização (Nakatsu and Iacovou 2009) e nos pontos negativos identificados pela prática de body shop no desenvolvimento de software da Gati, algumas ações preventivas podem ser estabelecidas:

- Realizar treinamentos constantes: quando se trata de pessoas, é imprescindível que haja treinamento e preparação antes de atuar diretamente com o cliente. Os profissionais devem estar motivados, demonstrar receptividade, habilidade, iniciativa e, sem dúvida, competência técnica e profissional, por meio de know-how e business-know-how;

- Diminuir o turnover: é inviável trocar constantemente o profissional que está atuando diretamente no cliente. Dividir o projeto em partes, alocando um profissional diferente para cada etapa, de forma semelhante às atividades desenvolvidas dentro da fábrica de software, dificulta as relações entre cliente e fornecedor. Adequar-se aos processos, cultura e dominar as questões de trabalho do cliente acarretam em tempo de estudo e adaptação. Alocação de outro profissional significa mais tempo despendido com atividades indiretas, 
ocasionando prejuízo financeiro, tanto para o cliente quanto para o fornecedor. Sem contar na insatisfação do cliente em lidar com rotatividade de pessoas;

- Comunicação contínua com o cliente: não basta utilizar meios de comunicação modernos, como Internet e telefone. A presença é a chave para a realização de uma boa comunicação. Reuniões ou visitas periódicas aos clientes ajudam a manter viva a comunicação entre ambas às partes;

- Estabelecer parceria entre cliente-fornecedor: atuar como parceiro estratégico entre a cadeia de clientes fortalece a parceria entre cliente-fornecedor, visto que ambos almejam o mesmo objetivo: satisfazer o cliente do cliente. Não basta realizar o que o cliente almeja, mas sim, atender a cadeia produtiva à frente;

- Prezar pela qualidade: o ponto chave da qualidade, conforme citado por Gilmore (1974), é a relação entre o previsto e o realizado, construir conforme o planejado, ou seja, ter como resultado o que foi exatamente previsto, seguindo um determinado padrão. Ter um padrão de documentação do sistema e dos processos evita conflitos e tende a agregar valor. Desta forma, é de fundamental importância que o cliente perceba a qualidade antes mesmo do início das atividades, para que, somente depois, se realize o serviço em body shop. Convidar o cliente para conhecer a empresa prestadora de serviços, a metodologia de trabalho, os workshops desenvolvidos e o RQG antes de assumir qualquer compromisso, ajuda não só na conquista do cliente, mas transmite segurança, credibilidade e qualidade;

- Gerenciar o projeto: deixar para o cliente gerenciar as atividades e projetos fragiliza a qualidade, principalmente em clientes sem experiências e que desejam mão de obra temporária e direta. Mesmo o cliente tendo o dever de realizar o gerenciamento, é uma boa prática intervir e realizar o acompanhamento, pois isso ajuda na interatividade, evita conflitos de interesses e fortalece os trabalhos.

\section{Considerações Finais}

Para diminuir os riscos de insucesso, a Gati adota o critério de realizar o planejamento junto ao cliente, antes do início de cada projeto e independentemente de o contrato de prestação de serviço ser firmado entre ambas as partes. Define-se, nesta primeira etapa, as atividades, artefatos e padrões que serão adotados durante o novo projeto.

O RQG, adotado pela fábrica de software da Gati, foi o ponto de início para o gerenciamento, servindo como uma baseline para o desenvolvimento e controle das atividades. Desta forma, os riscos não são evitados, mas sim, controlados e gerenciados.

Apesar de o cliente ser o responsável por realizar o gerenciamento das atividades de body shop, a Gati sempre realiza esta atividade, mesmo quando não contratada para tal fim. Porém, investe-se muito na comunicação e no repasse de experiências também com o cliente, com o objetivo de mostrar o quão importante é definir os processos e executar o gerenciamento. Desta forma, é repassado confiança e qualidade ao cliente, além de estimulá-lo a aplicar boas práticas.

Com a padronização do gerenciamento dos principais riscos da terceirização, a Gati passou a estar apta a participar do processo de terceirização com empresas de médio e grande porte. Além de melhorar as atividades e processos de trabalho, a 
qualidade passou a ser percebida pelo cliente, melhorando os laços e compromissos entre cliente-fornecedor.

\section{Referências}

Blomberg, J., Cefkin, M. and Rankin, Y. (2010) "Mapping and Visualizing Service Provider and Client Interactions: The Case for Participation", In: PDC '10 Proceedings of the 11th Biennial Participatory Design Conference, Australia, pages 294-296.

Chase, R. B., Aquilano, N. J. and Jacobs, R. (2004) "Administração da produção para a vantagem competitiva", Bookman, 10th edition.

Earl, M. J. (1996) "The Risks of Outsourcing IT", In: Sloan Management Review, volume 37, Spring, pages 26-32.

Gilmore, H. L. (1974) "Product conformance cost”, Quality Progress, June.

Lacity, M. and Hirschheim R. (1993) "Information Systems Outsourcing; Myths, Metaphors, and Realities", John Wiley \& Sons, New York.

Lima, M., Sapiro, A., Vilhena, J. B. and Gangana, M. (2009) "Gestão de marketing", FGV, 8th edition, Rio de Janeiro.

Nakatsu, R. T. and Iacovou , L. C. (2009) "A comparative study of important risk factors involved in offshore and domestic outsourcing of software development projects: A two-panel Delphi”, In: Information \& Management 46, p.57-68.

Mansur, R. (2007) “Governança de TI: metodologia, frameworks e melhores práticas”, Brasport, Rio de Janeiro.

Prado, E. P. V. and Takaoka, H. (2002) "Os Fatores que Motivam a Adoção da Terceirização da Tecnologia de Informação: uma Análise do Setor Industrial de São Paulo", In: Revista de Administração Contemporânea, volume 6, Curitiba.

Sá, M. P., Bomtempo, J. V. and Quental, C. (1998) "Terceirização no processamento final da indústria farmacêutica e veterinária", In: Revista de Administração Contemporânea, volume 2, Curitiba.

SEI - Software Engineering Institute (2006) "CMMI for Development", Version 1.2, Pittsburgh, PA.

Simões, C., Santos, G. and Rocha, A. R. (2010) "Implantação do Processo Aquisição no Contexto do Processo de Desenvolvimento de Software na Synapsis Brasil", In: IX Simpósio Brasileiro de Qualidade de Software, Belém, Brasil, p. 287-294.

Smuts, H., Kotzé, P., Merwee, A. V. D. and Loock, M. (2010) "Critical Success Factors for Information Systems Outsourcing Management: A Software Development Lifecycle View", In: Proceeding SAICSIT '10 Proceedings of the 2010 Annual Research Conference of the South African Institute of Computer Scientists and Information Technologists, South Africa, pages 304-313. 